\title{
Ambient air quality and the effects of air pollutants on otolaryngology in Beijing
}

\author{
Fengying Zhang • Jin Xu • Ziying Zhang • \\ Haiying Meng • Li Wang • Jinmei Lu • Wuyi Wang • \\ Thomas Krafft
}

Received: 25 March 2015 / Accepted: 26 June 2015 / Published online: 9 July 2015

(C) Springer International Publishing Switzerland 2015

\begin{abstract}
To investigate temporal patterns, pollution concentrations and the health effects of air pollutants in Beijing we carried out time-series analyses on daily concentrations of ambient air pollutants and daily numbers of outpatient visits for otolaryngology over 2 years (20112012) to identify possible health effects of air pollutants. The results showed that $\mathrm{PM}_{10}$ was the major air pollutant in Beijing and that air quality was slightly better in 2012 than in 2011. Seasonal differences were apparent for $\mathrm{SO}_{2}$ and $\mathrm{NO}_{2}$. Both the background and urban areas of Beijing experienced particulate matter pollution in 2011. In addition to local air pollution, Beijing was also affected by pollutants transported from other regions, especially during heavy air pollution episodes. $\mathrm{PM}_{10}, \mathrm{NO}_{2}$, and $\mathrm{SO}_{2}$ concentrations showed positive associations with numbers of outpatient visits for otolaryngology during winter.
\end{abstract}

\section{F. Zhang}

China National Environmental Monitoring Centre,

Beijing 100012, China

F. Zhang $\cdot$ L. Wang $\cdot$ T. Krafft

CAPHRI School of Public Health and Primary Care,

Maastricht University, Maastricht, the Netherlands

F. Zhang $(\bowtie) \cdot$ L. Wang $\cdot$ W. Wang $(\bowtie)$

Institute of Geographic Sciences and Natural Resources

Research, Chinese Academy of Sciences, 11A Datun Road,

Beijing 100101, China

e-mail: zhangfy@cnemc.cn

F. Zhang

e-mail: bichun886@163.com

W. Wang

e-mail: wangwy@igsnrr.ac.cn
$\mathrm{NO}_{2}$ and $\mathrm{SO}_{2}$ also had adverse ear, nose, and throat health effects outside of winter. The ear, nose, and throat health risks caused by air pollutants were higher during the winter than during the summer. $\mathrm{NO}_{2}$ had stronger influence on increased the likelihood of outpatient visits than $\mathrm{SO}_{2}$. The findings provide additional information about air quality and health effects of air pollution in Beijing.

Keywords Air pollutant · Temporal pattern · Pollutant concentration $\cdot$ Health effect $\cdot$ Beijing

\section{Introduction}

Research on air pollution is attracting significant interest worldwide (Lave and Seskin 2013; Leung et al. 2012).

\section{J. Xu}

Department of Otolaryngology-Head and Neck Surgery,

Beijing Hospital, Ministry of Public Health, Beijing 100730, China

\section{Z. Zhang}

Beijing Meteorological Bureau, Beijing 100089, China

H. Meng

Beijing Center for Diseases Prevention and Control, Beijing 100013, China

J. Lu

Department of Engineering and Safety, University of Tromsø, N-9037 Tromsø, Norway 
Air pollution has been found to have serious effects on public health in China (Chen et al. 2013). In a move to improve air quality, protect the climate, and reduce the health burden of air pollution, the Chinese Government issued a new National Ambient Air Quality Standard (GB3095-2012) in 2012 to replace an older one (GB3095-1996). The new air quality standard will be carried out step-by-step until 31 December 2015. Air quality assessments based on GB3095-2012 are urgently needed for further implementation of the standard.

Much research has shown that air pollution exposure increases the risk of mortality (Welty and Zeger 2005; Breitner et al. 2011), morbidity (Schleicher et al. 2011; Gold and Samet 2013), hospital admissions (Lall et al. 2011), outpatient visits (Guo et al. 2010), and diminished life expectancy and longevity (Wang et al. 2014). Early-life exposure to ambient air pollution may increase the risk of upper and lower respiratory tract infections in infants (Aguilera et al. 2013). Modest, but consistent, associations were found between some measures of air pollution and otitis media in a large birth cohort exposed to relatively low levels of ambient air pollution (MacIntyre et al. 2011). Consistent evidence was also found for an association between air pollution and pneumonia during early childhood, as well as some evidence for an association with otitis media (MacIntyre et al. 2014). Elevated levels of air pollutants increased respiratory tract complaints in children (Altuğ et al. 2014). Air pollution exposure has also been associated with olfactory dysfunction and olfactory bulbs pathology (Calderón-Garcidueñas et al. 2010). Higher particulate matter $\left(\mathrm{PM}_{10}\right), \mathrm{SO}_{2}$, and $\mathrm{NO}_{2}$ concentrations were associated with increased likelihood of hospital visits for allergic rhinitis in Beijing (Zhang et al. 2013; Zhang et al. 2011b). Better air quality was significantly associated with low prevalence of pediatric frequent ear infections, and improvements in air quality have been implicated in decreased rates of pediatric ear infections over time (Bhattacharyya and Shapiro 2010). Though these studies indicated that air pollutants influence an individual's ear, nose, and throat health, systematic studies focused on air quality and the health of adults' ears, noses, and throats (ENTs) are rare.

Beijing is the capital city of China and local air quality has attracted much concern (Zhang et al. 2007; Breitner et al. 2011). We carried out time-series analyses on daily concentrations of ambient air pollutants and daily numbers of outpatient consultations for otolaryngology in Beijing from 1 January 2011 to 31 December
2012. A non-parametric generalized additive model (GAM) was used to analyze exposure-response relationships between three air pollutants $\left(\mathrm{PM}_{10}, \mathrm{SO}_{2}\right.$, and $\left.\mathrm{NO}_{2}\right)$ and daily outpatient visits for otolaryngology. The objective of this study was to characterize temporal variations of ambient air pollutants, evaluate the ambient air quality of Beijing, and identify possible health effects of air pollutants on individuals' ENTs.

\section{Data and methodology}

Air pollutant monitoring and meteorological data

Daily $\mathrm{PM}_{10}, \mathrm{SO}_{2}$, and $\mathrm{NO}_{2}$ concentrations were obtained from the Beijing Municipal Environmental Protection Monitoring Center. The data was available as averages derived from the monitoring data of 11 state-controlled monitoring stations distributed across Beijing.

To quantify the air quality and air pollution concentrations in Beijing, daily monitoring data from one of the stations mentioned above (Dongsi) and one background monitoring station (Dingling) were obtained. The Dongsi air quality monitoring station is located in the Dongcheng District and is an urban environmental assessment site which is mainly used to assess regional air quality and its variations. Dingling is the urban background site for Beijing and is used to for quantifying pollution concentrations that are not influenced by the urban environment.

Daily temperatures, relative humidities, and other meteorological data for Beijing were obtained from the Beijing Meteorological Bureau.

\section{Outpatient visits for otolaryngology}

The numbers of outpatient consultations for otolaryngology from 1 January 2011 to 31 December 2012 were obtained from the Department of Otolaryngology-Head and Neck Surgery, Beijing Hospital, Ministry of Public Health. Beijing Hospital is a leading class 3, grade Alevel hospital located in the Dong Cheng District that serves a large catchment within central Beijing. The hospital is open to the general public, providing largescale, comprehensive, integrated health services, including medical treatment, teaching and education, scientific research, and disease prevention.

Only one visit per individual patient per day was included in the tabulation of daily visit counts. 
Subsequent follow-up visits that occurred within 30 days of the initial consultation were also not included in the count.

The Ethics Review Board of Beijing Hospital, Ministry of Public Health, and the Ethics Review Board of the Institute of Geographic Sciences and Natural Resources Research, CAS approved this study. Our study did not involve any patient's personal information.

\section{Data analysis}

\section{Spatio-temporal patterns of air pollutants}

Statistical analyses were used to study the temporal patterns of air pollutants in Beijing. Daily concentrations of air pollutants from 1 January 2011 to 31 December 2012 at the two monitoring stations discussed in the air pollutant monitoring and meteorological data section were evaluated.

\section{Health effect of air pollutants on individual's ENT}

Consistent with other time-series studies (Bhaskaran et al. 2013; Zhang et al. 2011b), we used the GAM to analyze outpatient visits, air pollutant concentrations, and covariates (meteorological factors, time trend, day of the week). Because the daily number of outpatient visits for otolaryngology were small and typically followed a Poisson distribution (Dominici et al. 2002; Caillaud et al. 2014), the core analysis involved GAM using log-link and Poisson uncertainty that accounted for smooth fluctuations in the daily numbers of consultations for otolaryngology.

$\log \left[E\left(Y_{t}\right)\right]=\alpha+\sum_{i=1}^{q} \beta_{i}\left(X_{i}\right)+\sum_{j=1}^{p} f_{j}\left(Z_{j}, d f\right)+W_{t}($ week $)$

Here $E\left(Y_{t}\right)$ represents the expected numbers of outpatient visit at day $t ; \beta$ represents the log-relative rate of outpatient visit associated with an unit increase of air pollutants; $X i$ indicates the concentrations of pollutants at day $t ; W_{t}($ week $)$ is the dummy variable for day of the week. $\sum_{j=1}^{p} f_{j}\left(Z_{j}, d f\right)$ is the non-parametric spline function of calendar time, temperature, and humidity. A detailed introduction to the GAM has been described in previous studies (Wood and Augustin 2002; Wood 2006).
We performed sensitivity analyses using Welty's method (Welty and Zeger 2005). We initialized the $d f$ as $7 d f$ yyear for time, $3 d f$ for temperature and barometric pressure, $5 d f$ for humidity. We fitted both singlepollutants models and multi-pollutant models (models with a different combination of two or three pollutants per model) to assess the stability of pollutants' effect.

We examined the effect of air pollutants with different lag (L) structures consisting of single-day lag (from L0-L3) and multi-day lag (L01-L03), where a lag of 0 day (L0) corresponded to pollution on the day and a lag of 1 day (L1) referred to pollution on the previous day. In multi-day lag models, L03 corresponded to 4-day moving averages of pollutant concentrations for the current and previous 3 days (Lall et al. 2011). The meteorological factors used in the lag models were those from the present day.

Seasonality was differentiated on the basis of heating/non-heating periods over the winter (heating period) in Beijing (from October to the following March) and the summer (non-heating period; from April to September). Because major parts of Beijing are still provided with central heating from coal burning power plants, air pollution loads during the heating season increased significantly. Our seasonal analysis followed the method introduced by Peng et al. (Peng et al. 2005).

All statistical analyses were conducted in $\mathrm{R}$ 3.1.0 using the MGCV package. The results obtained were expressed as the relative risk (RR) percentage change in the number of consultations for otolaryngology per $10 \mu \mathrm{g} / \mathrm{m}^{3}$ increase in air pollutant concentrations. The calculation of RR is presented in Eq. 2:

$\mathrm{RR}=e^{\beta \times \Delta \mathrm{C}}$,

where $\Delta C$ is the change in air pollutant concentration. In this study we used $10 \mu \mathrm{g} / \mathrm{m}^{3}$ for comparison with similar studies conducted in other locations across China.

\section{Results}

Overview and statistical results

Table 1 provides a statistical summary of the air pollutants studied, meteorological variables, and outpatient numbers on an annual and seasonal basis.

During the study period, the annual average temperature and humidity were $13.2{ }^{\circ} \mathrm{C}$ and $50.4 \%$, respectively. Daily temperatures ranged from -9.5 to $31.3{ }^{\circ} \mathrm{C}$ 
Table 1 Statistical characteristic of air pollutants, meteorological factors, and outpatient numbers

\begin{tabular}{|c|c|c|c|c|c|c|c|c|c|c|}
\hline \multirow[t]{2}{*}{ Variables } & & \multicolumn{3}{|l|}{ Average } & \multirow[t]{2}{*}{$\mathrm{SD}$} & \multicolumn{5}{|c|}{ percentage } \\
\hline & & All year & Winter & Summer & & Min & $25 \%$ & Median & $75 \%$ & Max \\
\hline \multirow[t]{3}{*}{ Air pollutants, $\mu \mathrm{g} / \mathrm{m}^{3}$} & $\mathrm{SO}_{2}$ & 28.4 & 41.9 & 15 & 27 & 5 & 9.1 & 18 & 38 & 166.8 \\
\hline & $\mathrm{NO}_{2}$ & 53.9 & 61.8 & 46 & 22.5 & 14 & 38 & 49.2 & 66.1 & 160.2 \\
\hline & $\mathrm{PM}_{10}$ & 110.6 & 109.5 & 111.7 & 74.9 & 7 & 55 & 95 & 150 & 573 \\
\hline \multirow[t]{3}{*}{ Temperature, ${ }^{\circ} \mathrm{C}$} & Ave & 13.2 & 3.3 & 23 & 11.5 & -9.5 & 1.7 & 15.5 & 23.8 & 31.3 \\
\hline & Max & 18.2 & 8.3 & 28.1 & 11.8 & -5.8 & 6.9 & 20.9 & 28.8 & 38 \\
\hline & Min & 8.4 & -1.2 & 18 & 11.4 & -13.7 & -2.3 & 10.2 & 19 & 26.7 \\
\hline \multirow[t]{3}{*}{ Pressure, $\mathrm{hPa}$} & Ave & 1012.6 & 1021.1 & 1004.2 & 10.5 & 990.4 & 1003.5 & 1012.6 & 1021.4 & 1037.3 \\
\hline & Max & 1015.2 & 1024 & 1006.5 & 10.8 & 992.6 & 1005.5 & 1015.5 & 1024.1 & 1040.3 \\
\hline & Min & 1009.6 & 1017.8 & 1001.3 & 10.4 & 987.7 & 1001 & 1009.1 & 1017.8 & 1034.5 \\
\hline \multirow[t]{2}{*}{ Humidity, \% } & Ave & 50.4 & 44.8 & 55.9 & 20.9 & 9 & 31 & 52 & 67 & 97 \\
\hline & Min & 30.1 & 25.9 & 34.2 & 18.2 & 5 & 15 & 25 & 42 & 85 \\
\hline \multirow[t]{2}{*}{ Wind speed $\mathrm{m} / \mathrm{s}$} & Ave & 2.2 & 2.2 & 2.3 & 0.9 & 0.6 & 1.6 & 2.1 & 2.6 & 5.8 \\
\hline & Max & 4.9 & 4.8 & 5 & 1.8 & 1.7 & 3.5 & 4.6 & 6.1 & 12 \\
\hline Daily numbers of outpatient & & 198 & 192 & 205 & 39 & 87 & 173 & 199 & 224 & 314 \\
\hline
\end{tabular}

and daily relative humidities ranged from 9 to $97 \%$, reflecting the sub-humid, warm temperate, continental monsoon climate of Beijing.

Figure 1 presents the temporal variability of the three air pollutants studied and the daily number of outpatient visits for otolaryngology. Over the 2 years, average daily
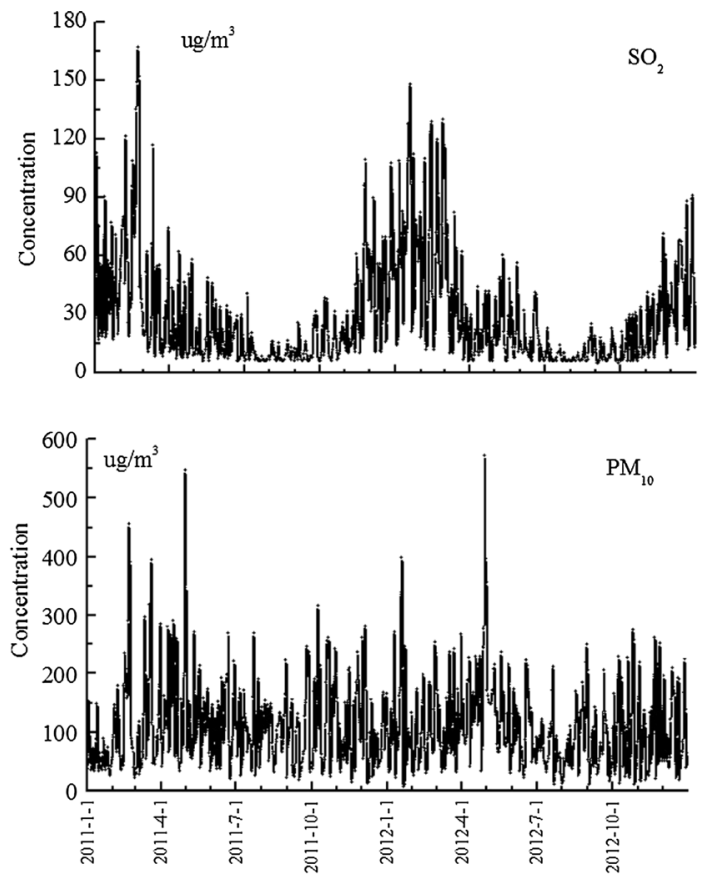

concentrations of $\mathrm{PM}_{10}, \mathrm{SO}_{2}$, and $\mathrm{NO}_{2}$ were 110.6, 28.4, and $53.9 \mu \mathrm{g} / \mathrm{m}^{3}$, respectively. Concentrations of $\mathrm{SO}_{2}$ and $\mathrm{NO}_{2}$ showed clear seasonal differences, with higher concentrations occurring during the winter. Though $\mathrm{PM}_{10}$ concentrations had some peak values, there was no seasonality apparent.
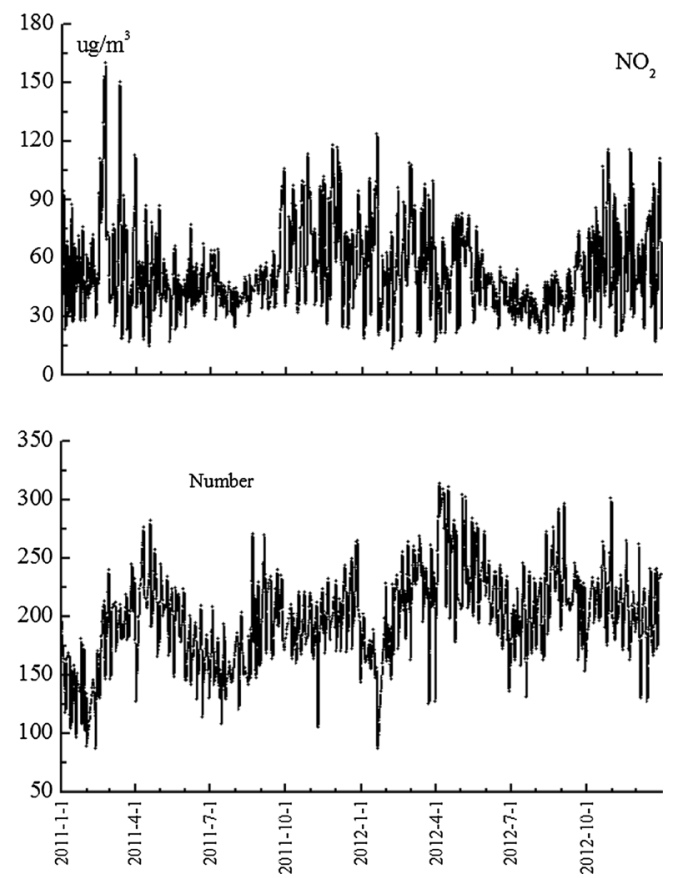

Fig. 1 Daily concentrations of air pollutants and numbers of outpatient visits for otolaryngology 
A total of 145,085 outpatients attended the Department of Otolaryngology-Head and Neck Surgery, Beijing Hospital. Daily patient numbers ranged from 87 to 314 . Average daily outpatient numbers were higher during the summer than during the winter and the highest number of outpatient visits occurred in April and May.

Pearson correlation coefficients among different air pollutants and meteorological factors are presented in Table 2. Significant correlations were identified among the three air pollutants, probably because emissions from domestic heating are a common source.

\section{Assessments of air quality}

In this study, we assessed daily ambient air quality based on GB3095-2012 and the results were expressed as the air quality class. The annual air quality was worse than class 2 in 2011 and the annual average concentrations of $\mathrm{PM}_{10}, \mathrm{SO}_{2}$, and $\mathrm{NO}_{2}$ were 113,28 , and $56 \mu \mathrm{g} / \mathrm{m}^{3}$, respectively. There were 101 days when air pollutant concentrations exceeded the class 2 limits. The annual average concentrations of $\mathrm{PM}_{10}, \mathrm{SO}_{2}$, and $\mathrm{NO}_{2}$ were 109,28 , and $52 \mu \mathrm{g} / \mathrm{m}^{3}$, respectively, and the annual air quality was worse than class 2 in 2012. There were 91 days when air pollutant concentrations exceeded the GB3095-2012 standard limits. By any measure, air quality showed some improves from 2011 to 2012 in Beijing.

Over the 2 years studied, $\mathrm{PM}_{10}$ was the major air pollutant in Beijing. Overall, 181 days featured heavy $\mathrm{PM}_{10}$ pollution where daily $\mathrm{PM}_{10}$ concentrations exceeded $150 \mu \mathrm{g} / \mathrm{m}^{3}$. $\mathrm{PM}_{10}$ concentration ranges were wide and the largest concentrations were higher than the recommended limits in this study. The maximum daily $\mathrm{PM}_{10}$ concentration $\left(573 \mu \mathrm{g} / \mathrm{m}^{3}\right)$ was three times greater than the class 2 limit $\left(150 \mu \mathrm{g} / \mathrm{m}^{3}\right) . \mathrm{SO}_{2}$ and $\mathrm{NO}_{2}$ concentrations were also high at times and exceeded the class 2 limits occasionally.

Figure 2 presents time-series analyses of air pollutant concentrations at Dingling and Dongsi in 2011.

Daily air pollutant concentrations at Dongsi were higher than at Dingling, indicating that urban air pollution sources were present in the Dongsi area. According to GB3095-2012, 25.2 \% days in 2011 had heavy air pollution at Dongsi, and Dingling also experienced some heavy air pollution days, suggesting that pollution from outside the urban area was being transported into the city. The annual average $\mathrm{NO}_{2}$ and $\mathrm{SO}_{2}$ concentrations at Dingling met class 2 standards $\left(60 \mu \mathrm{g} / \mathrm{m}^{3}\right.$ for $\mathrm{SO}_{2}$ and $40 \mu \mathrm{g} / \mathrm{m}^{3}$ for $\mathrm{NO}_{2}$ ). The annual average $\mathrm{SO}_{2}$ concentration at Dongsi met the class 2 standard, but the annual average $\mathrm{NO}_{2}$ concentration failed to meet the class 2 standard. Annual average $\mathrm{PM}_{10}$ concentrations at Dingling and Dongsi failed to meet the class 2 standard. Statistical results and air quality classifications for the two sites are presented in Table 3.

Associations among air pollutants and individuals' ENTs issues

Table 4 presents the RRs (95\% confidence intervals (CI)) of outpatient visits for ENT issues with every $10 \mu \mathrm{g} / \mathrm{m}^{3}$ increase in air pollutant concentrations.

To identify any possible time delays of air pollutants on health effects in the clinical manifestation of symptoms, we analyzed the lag effects of air pollutants on daily numbers of outpatient visits. Changes in RRs for the numbers of outpatient visits for otolaryngology with a $10 \mu \mathrm{g} / \mathrm{m}^{3}$ increase in pollutant concentrations for single-day measures (L0-L3) and moving average

Table 2 Correlation coefficients between air pollutants and meteorological factors

\begin{tabular}{|c|c|c|c|c|c|c|c|}
\hline & $\mathrm{SO}_{2}$ & $\mathrm{NO}_{2}$ & $\mathrm{PM}_{10}$ & Temperature & Pressure & Humidity & Wind speed \\
\hline $\mathrm{SO}_{2}$ & 1 & & & & & & \\
\hline $\mathrm{NO}_{2}$ & $0.698^{\mathrm{a}}$ & 1 & & & & & \\
\hline $\mathrm{PM}_{10}$ & $0.460^{\mathrm{a}}$ & $0.662^{\mathrm{a}}$ & 1 & & & & \\
\hline Temperature & $-0.587^{\mathrm{a}}$ & $-0.259^{\mathrm{a}}$ & 0.054 & 1 & & & \\
\hline Pressure & $0.414^{\mathrm{a}}$ & $0.182^{\mathrm{a}}$ & $-0.144^{\mathrm{a}}$ & $-0.888^{\mathrm{a}}$ & 1 & & \\
\hline Humidity & -0.050 & $0.251^{\mathrm{a}}$ & $0.237^{\mathrm{a}}$ & 0.376 & $-0.369^{\mathrm{a}}$ & 1 & \\
\hline Wind speed & -0.240 & $-0.418^{\mathrm{a}}$ & $-0.157^{\mathrm{a}}$ & -0.010 & -0.040 & $-0.449^{\mathrm{a}}$ & 1 \\
\hline
\end{tabular}

${ }^{\text {a }}$ Correlation is significant at the 0.01 level (2-tailed) 

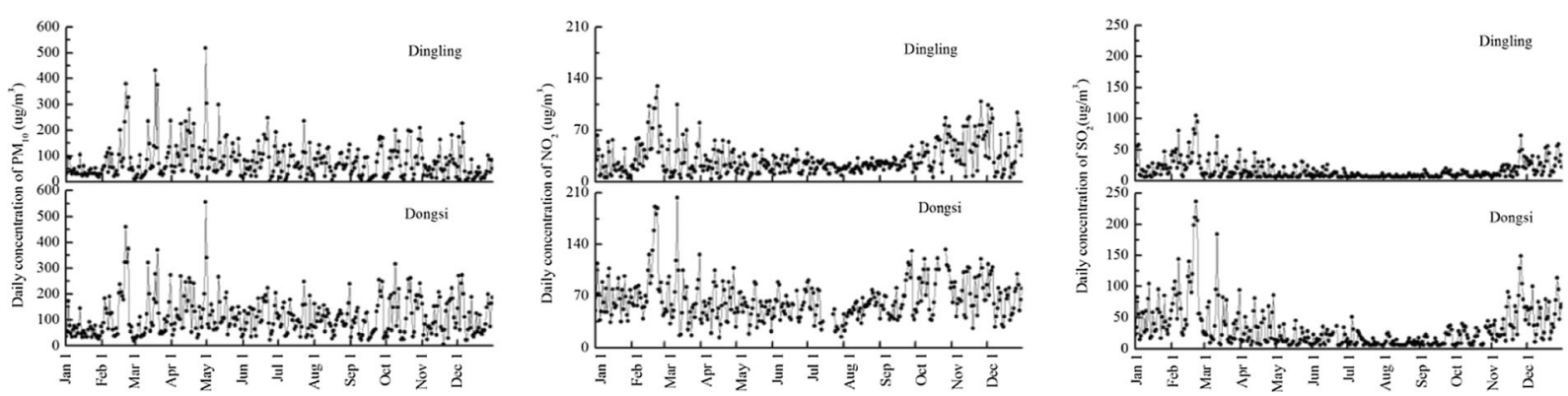

Fig. 2 Daily concentrations of $\mathrm{SO}_{2}, \mathrm{NO}_{2}$, and $\mathrm{PM}_{10}$ at Dingling and Dongsi in 2011

measures (L01-L03) are also provided in Table 4. While running the models, we also considered lags of more than 3 days for each of the pollutants, but very few associations were identified and these results have been excluded from further analyses.

Over the whole study period, there was no obvious relationship between $\mathrm{PM}_{10}$ concentration changes and the number of outpatient visits. $\mathrm{NO}_{2}$ and $\mathrm{SO}_{2}$ concentration changes showed positive associations with increases in daily numbers of outpatient visits for otolaryngology. The largest relative risks were for elevated pollutant concentrations on day zero, and the relative risks of these two air pollutants decreased as lag days increased for the single lag day and moving average lag day models. Compared with $\mathrm{SO}_{2}, \mathrm{NO}_{2}$ had a stronger influence on the likelihood of outpatient visits for ENT issues.

Seasonal differences in RRs on individuals' ENTs are shown in Table 4. For each of the air pollutants, the RRs during winter were higher than during summer. Though no obvious ENT effects of $\mathrm{PM}_{10}$ could be identified over the whole research period, a positive association between $\mathrm{PM}_{10}$ concentrations and daily numbers of outpatient visits for otolaryngology were observed during the winter. We did not consider the effects of all three pollutants together in one model.

\section{Discussion}

In this study, we analyzed the temporal patterns of air pollutant concentrations in Beijing from 1 January 2011 to 31 December 2012. We also performed time-series analyses on daily concentrations of ambient air pollutants and daily numbers of outpatient visits for otolaryngology to identify possible ENT effects on exposed individuals. The results provide additional information about air quality and the health effects of air pollution in Beijing.

Over the 2 years studied, daily $\mathrm{PM}_{10}$ concentrations ranged from 7 to $573 \mu \mathrm{g} / \mathrm{m}^{3}$, with an average concentration of $110.6 \mu \mathrm{g} / \mathrm{m}^{3}$. Daily $\mathrm{NO}_{2}$ concentrations ranged from 14 to $160.2 \mu \mathrm{g} / \mathrm{m}^{3}$, with an average concentration of $53.9 \mu \mathrm{g} / \mathrm{m}^{3}$. $\mathrm{SO}_{2}$ had minimum, maximum, and average daily concentrations of 5, 166.8, and $28.4 \mu \mathrm{g} / \mathrm{m}^{3}$, respectively. Daily $\mathrm{SO}_{2}$ and $\mathrm{NO}_{2}$ concentrations had clear seasonality, with peak concentrations occurring during the winter. Daily patterns for the concentrations of $\mathrm{SO}_{2}$ and $\mathrm{NO}_{2}$ in this study were consistent with previous studies (Zhang et al. 2011a; Zhang et al. 2011c). The pollutant concentrations were typically higher during the winter from November to the following March (Zhang et al. 2011c). Daily $\mathrm{PM}_{10}$ concentrations did not show much seasonal variation. This could be because the pollution sources for $\mathrm{PM}_{10}$ were

Table 3 Statistical data and air quality classifications at the two monitoring stations in 2011

\begin{tabular}{|c|c|c|c|c|c|c|c|c|c|c|}
\hline \multirow[t]{2}{*}{ Pollutants } & \multicolumn{5}{|c|}{ Dingling, $\mu \mathrm{g} / \mathrm{m}^{3}$} & \multicolumn{5}{|c|}{ Dongsi, $\mu \mathrm{g} / \mathrm{m}^{3}$} \\
\hline & Min & Max & Ave & $>\mathrm{C} 1$ & $>\mathrm{C} 2$ & Min & Max & Ave & $>\mathrm{C} 1$ & $>\mathrm{C} 2$ \\
\hline $\mathrm{SO}_{2}$ & 6 & 105 & 16.7 & $4.1 \%$ & 0 & 6 & 236 & 33.7 & $20.9 \%$ & $1.4 \%$ \\
\hline $\mathrm{NO}_{2}$ & 4 & 130 & 31.6 & $4.1 \%$ & 0 & 14 & 203 & 65.2 & $24.9 \%$ & 0 \\
\hline $\mathrm{PM}_{10}$ & 3 & 518 & 80.7 & $59.7 \%$ & $10.1 \%$ & 6 & 555 & 112.3 & $78.4 \%$ & $25.2 \%$ \\
\hline
\end{tabular}

$>C 1$ percentage of days worse than class $1,>C 2$ percentage of days worse than class 2 
Table 4 RRs for outpatient visits with every $10 \mu \mathrm{g} / \mathrm{m}^{3}$ increase in air pollutant concentrations

\begin{tabular}{|c|c|c|c|c|c|c|}
\hline \multirow[t]{2}{*}{ Lag day/season } & \multicolumn{2}{|l|}{$\mathrm{PM}_{10}$} & \multicolumn{2}{|l|}{$\mathrm{NO}_{2}$} & \multicolumn{2}{|l|}{$\mathrm{SO}_{2}$} \\
\hline & $\mathrm{RR}$ & $95 \% \mathrm{CI}$ & $\mathrm{RR}$ & $95 \% \mathrm{CI}$ & $\mathrm{RR}$ & $95 \% \mathrm{CI}$ \\
\hline L0 & -0.082 & $-0.166 \sim 0.003$ & 0.977 & $0.940 \sim 1.014$ & 0.659 & $0.624 \sim 0.695$ \\
\hline $\mathrm{L} 1$ & -0.184 & $-0.368 \sim 0.001$ & 0.334 & $0.303 \sim 0.365$ & 0.100 & $0.069 \sim 0.132$ \\
\hline $\mathrm{L} 2$ & -0.135 & $-0.270 \sim 0.001$ & -0.088 & $-0.181 \sim 0.005$ & -0.154 & $-0.310 \sim 0.003$ \\
\hline L3 & -0.127 & $-0.257 \sim 0.003$ & -0.234 & $-0.471 \sim 0.002$ & -0.229 & $-0.459 \sim 0.002$ \\
\hline L01 & -0.201 & $-0.403 \sim 0.001$ & 0.889 & $0.848 \sim 0.93$ & 0.519 & $0.479 \sim 0.560$ \\
\hline L02 & -0.268 & $-0.538 \sim 0.001$ & 0.637 & $0.592 \sim 0.681$ & 0.317 & $0.272 \sim 0.361$ \\
\hline L03 & -0.333 & $-0.666 \sim 0.001$ & 0.357 & $0.308 \sim 0.405$ & 0.099 & $0.050 \sim 0.147$ \\
\hline Summer & -0.167 & $-0.341 \sim 0.006$ & -0.649 & $-1.301 \sim 0.003$ & 0.021 & $-0.073 \sim 0.114$ \\
\hline Winter & 0.035 & $0.022 \sim 0.049$ & 1.325 & $1.280 \sim 1.370$ & 0.113 & $0.073 \sim 0.152$ \\
\hline
\end{tabular}

varied and included traffic exhaust and coal-related pollution that have important impacts on air quality (Zhang et al. 2011c). The average concentrations were higher than the median concentrations for the air pollutants studied, indicating that extremely high pollution episodes were driving the average concentrations. Significant correlations among the three air pollutants indicate emissions from domestic heating are a common source.

Compared with 2011, annual air pollutant concentrations and number of pollution days decreased slightly in 2012, indicating that ambient air quality in Beijing had improved slightly. According to GB3095-2012, PM $_{10}$ was the major air pollutant in Beijing during the study period and $25 \%$ of days featured heavy $\mathrm{PM}_{10}$ pollution where daily $\mathrm{PM}_{10}$ concentrations exceeded $150 \mu \mathrm{g} / \mathrm{m}^{3}$.

In 2011, the annual average $\mathrm{PM}_{10}$ concentration was $80.7 \mu \mathrm{g} / \mathrm{m}^{3}$ at Dingling and $112.3 \mu \mathrm{g} / \mathrm{m}^{3}$ at Dongsi. $\mathrm{PM}_{10}$ concentrations at these two sites failed to meet the class 2 standard. In 2011, 25.2\% of days were classified as heavy pollution days and daily air pollutant concentrations at Dongsi were higher than Dingling, which indicated extra urban air pollution sources existed at Dongsi. There were also some heavy air pollution days at the background site, which indicated that regional sources were influencing air quality in Beijing at these times.

Daily numbers of outpatient visits for otolaryngology ranged from 87 to 314 at Beijing Hospital, with an average of 198 per day. The average number of outpatient visits was higher during the summer than during the winter.
Associations between atmospheric pollutants and otitis media have been well documented and statistically significant associations between improvements in air quality and reductions in the frequency of ear infection prevalence have been reported (Bhattacharyya and Shapiro 2010). Exposure to ambient air pollution also increases the risk of upper and lower respiratory tract infections (Aguilera et al. 2013; Altuğ et al. 2014) and increases olfactory dysfunction and olfactory bulb pathology (Calderón-Garcidueñas et al. 2010).

In our study, we combined ear, nose, and throat issues together and found positive associations between air pollutant concentrations $\left(\mathrm{NO}_{2}\right.$ and $\left.\mathrm{SO}_{2}\right)$ and daily numbers of outpatient visits for otolaryngology, which is consistent with previous studies (Aguilera et al. 2013; Altuğ et al. 2014; Bhattacharyya and Shapiro 2010). The largest relative risks were found for day 0 , and the relative risks posed by these two air pollutants decreased by lag day when concentrations were considered for single lag day and moving average lag day analyses. Compared to $\mathrm{SO}_{2}, \mathrm{NO}_{2}$ had a stronger influence on increased likelihood of outpatient visits. There was no obvious relationship between $\mathrm{PM}_{10}$ concentration changes and number of outpatient visits. RRs during winter were higher than those during the summer for the three air pollutants. A positive association between $\mathrm{PM}_{10}$ concentrations and daily numbers of outpatient visits for otolaryngology was identified only during winter. Pearson correlation coefficients between air pollutants and patient numbers also indicated that the numbers of outpatient visits for otolaryngology were significantly correlated with the three air pollutants during winter, indicating that the air pollutants had short-term 
effects on individuals' ENTs that exacerbated ENT symptoms and increased hospital visits.

Though the average daily numbers of outpatient visits for otolaryngology were higher during summer, the daily average concentrations of $\mathrm{SO}_{2}$ and $\mathrm{NO}_{2}$ were higher during winter. RRs during winter were higher than during summer for the three air pollutants studied. One possible explanation for this result is that besides the air pollutants studied, other factors, like pollen concentrations, could influence the health of ENTs during the summer (Caillaud et al. 2014). Air pollutants can trigger the release of allergen-containing granules from grass pollen and increase the bioavailability of airborne pollen allergens (Zhang et al. 2011b). Combinations of air pollutants and pollen can accelerate the occurrence of allergic rhinitis, and increased pollen levels were significantly associated with hospital outpatient visits for allergic rhinitis (Zhang et al. 2012; Zhang et al. 2011b). Daily numbers of outpatient visits for allergic rhinitis showed a similar time-series to that of pollen levels during the summer (Zhang et al. 2012).

Our study also had some limitations. We were only able to obtain data from one major hospital in Beijing. Because the catchment boundaries of hospitals in central Beijing are not clearly defined, it was not possible to establish population characteristics within the catchment area. Because $\mathrm{PM}_{2.5}$ pollution data were not yet available, we had to limit our analysis to $\mathrm{PM}_{10}$. Average values derived from the monitoring data of 11 statecontrolled monitoring stations distributed across Beijing were used as exposure concentrations, but a more accurate exposure assessment and proper catchment boundaries for the hospital are important factors that should be considered further. Further investigations on the relationships among meteorological factors, air pollutants, time-series activity, personal pollutant exposure, socioeconomics, and human health at a city level are required.

\section{Conclusion}

$\mathrm{PM}_{10}$ was the major air pollutant in Beijing and $25 \%$ of days had heavy air pollution over the 2 years studied (2011 and 2012). Beijing's air quality improved slightly in 2012. Seasonal differences were identified for $\mathrm{SO}_{2}$ and $\mathrm{NO}_{2}$ concentrations, and no seasonality was apparent for $\mathrm{PM}_{10}$. During air pollution episodes, concentrations of all three air pollutants studied were high. Both the background and urban areas of Beijing had high particulate matter pollution in 2011 , and the city suffered from regional pollution in addition to local emissions on some occasions. $\mathrm{PM}_{10}, \mathrm{NO}_{2}$, and $\mathrm{SO}_{2}$ showed positive associations with daily numbers of outpatient visits for otolaryngology during winter. $\mathrm{NO}_{2}$ and $\mathrm{SO}_{2}$ also had effects on individuals' ENTs during summer. The health risks on an individual's ENT caused by air pollutants were higher during the winter than during the summer, and $\mathrm{NO}_{2}$ had a stronger influence on the increased likelihood of outpatient visits than $\mathrm{SO}_{2}$. Our study provides evidence to health services policy makers for the need to be more proactive and to insure that sufficient resources are available to provide realtime public health alerts based on air quality so that those affected can be advised.

Acknowledgments The authors wish to thank all the staff members at Department of Otolaryngology-Head and Neck Surgery, Beijing Hospital, Ministry of Public Health for their strong support of this study. We thank the Beijing Municipal Environmental Monitoring Center and the Beijing Meteorological Office for providing the data. The present study was supported by the National Natural Science Foundation of China (No. 41371118 and No. 41401101), and Forestry Public Welfare Project of China (No. 201304301).

Conflict of interest The authors declare that they have no competing interests.

\section{References}

Aguilera, I., Pedersen, M., Garcia-Esteban, R., Ballester, F., Basterrechea, M., Esplugues, A., et al. (2013). Early-life exposure to outdoor air pollution and respiratory health, ear infections, and eczema in infants from the INMA study. Environmental Health Perspectives, 121(3), 387.

Altuğ, H., Gaga, E. O., Döğeroğlu, T., Brunekreef, B., Hoek, G., \& Van Doorn, W. (2014). Effects of ambient air pollution on respiratory tract complaints and airway inflammation in primary school children. Science of the Total Environment, 479, 201-209.

Bhaskaran, K., Gasparrini, A., Hajat, S., Smeeth, L., \& Armstrong, B. (2013). Time series regression studies in environmental epidemiology. International Journal of Epidemiology, 42(4), 1187-1195.

Bhattacharyya, N., \& Shapiro, N. L. (2010). Air quality improvement and the prevalence of frequent ear infections in children. Otolaryngology-Head and Neck Surgery, 142(2), 242246.

Breitner, S., Liu, L., Cyrys, J., Brüske, I., Franck, U., Schlink, U., et al. (2011). Sub-micrometer particulate air pollution and cardiovascular mortality in Beijing, China. Science of the 
Total Environment, 409(24), 5196-5204. doi:10.1016/j. scitotenv.2011.08.023.

Caillaud, D., Toloba, Y., Raobison, R., Besancenot, J., Thibaudon, M., Martin, S., et al. (2014). Health impact of exposure to pollens: a review of epidemiological studies. Revue des Maladies Respiratoires, 31(2), 142-149.

Calderón-Garcidueñas, L., Franco-Lira, M., Henríquez-Roldán, C., Osnaya, N., González-Maciel, A., Reynoso-Robles, R., et al. (2010). Urban air pollution: influences on olfactory function and pathology in exposed children and young adults. Experimental and Toxicologic Pathology, 62(1), 91102.

Chen, Z., Wang, J.-N., Ma, G.-X., \& Zhang, Y.-S. (2013). China tackles the health effects of air pollution. The Lancet, 382(9909), 1959-1960.

Dominici, F., McDermott, A., Zeger, S. L., \& Samet, J. M. (2002). On the use of generalized additive models in time-series studies of air pollution and health. American Journal of Epidemiology, 156(3), 193-203.

Gold, D. R., \& Samet, J. M. (2013). Air pollution, climate, and heart disease. Circulation, 128(21), e411-e414.

Guo, Y., Tong, S., Zhang, Y., Barnett, A. G., Jia, Y., \& Pan, X. (2010). The relationship between particulate air pollution and emergency hospital visits for hypertension in Beijing, China. Science of the Total Environment, 408(20), 4446-4450. doi: 10.1016/j.scitotenv.2010.06.042.

Lall, R., Ito, K., \& Thurston, G. D. (2011). Distributed lag analyses of daily hospital admissions and source-apportioned fine particle air pollution. Environmental Health Perspectives, 119(4), 455-460. doi:10.1289/ehp.1002638.

Lave, L. B., \& Seskin, E. P. (2013). Air pollution and human health (Vol. 6): Routledge.

Leung, T. F., Ko, F. W.-s., \& Wong, G. W.-k. (2012). Roles of pollution in the prevalence and exacerbations of allergic diseases in Asia. Journal of Allergy and Clinical Immunology, 129(1), 42-47. doi:10.1016/j.jaci.2011.11.031.

MacIntyre, E. A., Gehring, U., Mölter, A., Fuertes, E., Klümper, C., Krämer, U., et al. (2014). Air pollution and respiratory infections during early childhood: an analysis of 10 European birth cohorts within the ESCAPE Project. Environmental Health Perspectives, 122(1), 107.

MacIntyre, E. A., Karr, C. J., Koehoorn, M., Demers, P. A., Tamburic, L., Lencar, C., et al. (2011). Residential air pollution and otitis media during the first two years of life. Epidemiology, 22(1), 81-89.

Peng, R. D., Dominici, F., Pastor-Barriuso, R., Zeger, S. L., \& Samet, J. M. (2005). Seasonal analyses of air pollution and mortality in 100 US cities. American Journal of Epidemiology, 161(6), 585-594. doi:10.1093/aje/kwi075.
Schleicher, N. J., Norra, S., Chai, F., Chen, Y., Wang, S., Cen, K., et al. (2011). Temporal variability of trace metal mobility of urban particulate matter from Beijing - a contribution to health impact assessments of aerosols. Atmospheric Environment, 45(39), 7248-7265. doi:10.1016/j.atmosenv. 2011.08.067.

Wang, L., BingganWei, Li, Y., Li, H., Zhang, F., Rosenberg, M., et al (2014). A study of air pollutants influencing life expectancy and longevity from spatial perspective in China. Science of the Total Environment, 487, 57-64. doi:10.1016/ j.scitotenv.2014.03.142.

Welty, L. J., \& Zeger, S. L. (2005). Are the acute effects of particulate matter on mortality in the national morbidity, mortality, and air pollution study the result of inadequate control for weather and season? A sensitivity analysis using flexible distributed lag models. American Journal of Epidemiology, 162(1), 80-88. doi:10.1093/aje/kwi157.

Wood, S. (2006). Generalized additive models: an introduction with R: CRC press.

Wood, S. N., \& Augustin, N. H. (2002). GAMs with integrated model selection using penalized regression splines and applications to environmental modelling. Ecological Modelling, 157(2), 157-177.

Zhang, F., Krafft, T., Ye, B., Zhang, F., Zhang, J., Luo, H., et al. (2013). The lag effects and seasonal differences of air pollutants on allergic rhinitis in Beijing. Science of the Total Environment, 442, 172-176.

Zhang, F., Krafft, T., Zhang, D., Xu, J., \& Wang, W. (2012). The association between daily outpatient visits for allergic rhinitis and pollen levels in Beijing. Science of the Total Environment, 417-418, 39-44. doi:10.1016/j.scitotenv. 2011.12.021.

Zhang, F., Li, L., Krafft, T., Lv, J., Wang, W., \& Pei, D. (2011a). Study on the association between ambient air pollution and daily cardiovascular and respiratory mortality in an urban district of Beijing. International Journal of Environmental Research and Public Health, 8(6), 2109-2123.

Zhang, F. Y., Wang, W. Y., Lv, J. M., Krafft, T., \& Xu, J. (2011b). Time-series studies on air pollution and daily outpatient visits for allergic rhinitis in Beijing, China. Science of the Total Environment, 409(13), 2486-2492. doi:10.1016/j.scitotenv. 2011.04.007.

Zhang, J., Ouyang, Z., Miao, H., \& Wang, X. (2011c). Ambient air quality trends and driving factor analysis in Beijing, 19832007. Journal of Environmental Sciences, 23(12), 20192028.

Zhang, M., Song, Y., \& Cai, X. (2007). A health-based assessment of particulate air pollution in urban areas of Beijing in 2000 2004. Science of the Total Environment, 376(1-3), 100-108. doi:10.1016/j.scitotenv.2007.01.085. 